\title{
A pilot study evaluating the utility of commercially available antibodies for flow cytometric analysis of Panthera species lymphocytes
}

\author{
Tashnica Taime Sylvester ${ }^{*}$ (D), Sven David Charles Parsons, Paul David van Helden, Michele Ann Miller
} and Andre Gareth Loxton

\begin{abstract}
Background: The immune response against tuberculosis in lions is still poorly defined and our understanding is hampered by the lack of lion specific reagents. The process for producing antibodies against a specific antigen is laborious and not available to many research laboratories. As the search for antibody cross-reactivity is an important strategy for immunological studies in veterinary medicine, we have investigated the use of commercially available antibodies to characterize T cell subsets in African lions (Panthera leo).

Results: Commercially available antibodies were screened and investigated the influence of two different sample processing methods, as well as the effect of time delay on cell surface marker expression on lion lymphocytes. Using commercially available antibodies, we were able to identify $\mathrm{CD} 4^{+}, \mathrm{CD}^{+}, \mathrm{CD}^{+}, \mathrm{CD} 14^{+}, \mathrm{CD} 25^{+}, \mathrm{CD} 44^{+}$and $\mathrm{CD} 45^{+} \mathrm{T}$ lymphocytes in samples obtained by density gradient centrifugation as well as red cell lysis of lion whole blood. Two distinct lymphocyte populations, which differed in size and phenotype, were observed in the samples processed by density gradient centrifugation.
\end{abstract}

Conclusion: Commercially available antibodies are able to differentiate between T lymphocyte subsets including immune effector cells in African lion whole blood, and possibly give insight into unique specie phenotypes.

Keywords: African lion, Flow cytometery, Immunophenotype, Panthera leo

\section{Background}

The immune system is a complex and multi-faceted system which includes components such as memory and self-regulation. Flow cytometry is a commonly used tool in immunological research, making use of fluorophore -labelled antibodies to detect specific proteins expressed intracellularly and on cell membranes [1]. This technique is used to monitor immune responses to infection, track the phenotypic and functional characteristics of antigen-specific cells, and has more recently been used

\footnotetext{
*Correspondence: tammyolivier@gmail.com

NRF/DST Centre of Excellence for Biomedical Tuberculosis Research; South African Medical Research Council Centre for Tuberculosis Research; Division of Molecular Biology and Human Genetics, Faculty of Medicine and Health Sciences, Stellenbosch University, Cape Town, South Africa
}

for the routine clinical diagnosis, prognosis and monitoring of disease [1].

Understanding the influence of pathogens, such as Mycobacterium bovis and feline immunodeficiency virus (FIV), opportunistic organisms and environmental heterogeneity on wild lion populations is crucial as the loss of these apex predators can have devastating effects on the ecosystems they inhabit [2]. Despite this, there is currently little known about how health and immunity are shaped by $M$. bovis and FIV co-infection when the environment and the host and pathogen genotypes vary. Knowledge of comparative immunology of wildlife can further facilitate our understanding of the interactions between host responses, ecology, evolution and health [3]. Generally, wildlife populations have a high degree of genetic variation which affects the robustness of the 
immune response, possibly making investigations in these populations more reflective of what happens in humans compared to laboratory models [4]. However, research in non-model animal species, in particular those living in the wild [5] or wildlife species who may be reservoirs for disease, a lack of species specific reagents limit our current ability to easily characterize immune phenotypes in these species $[6,7]$. For this reason the de novo manufacturing of reagents or the evaluation of cross-reactive antibodies from related domestic species are needed to study species such as wild felids. Because no commercial antibodies have specifically been produced for use in flow cytometry in lions, the investigation and characterization of immune cell phenotypes in this species remains challenging. Despite these issues, through the use of cross-reactive antibodies, researchers have shown that FIV infection in lions is associated with lower levels of circulating CD4-positive T cells [8-10] as well as an increase in the $C D 8 \beta^{\text {high }}$ subset $[9,10]$.

The aim of this study was to identify commercially available antibodies that can be used for flow cytometry in Panthera species. Furthermore, we sought to compare the effects of density gradient centrifugation and red cell lysis of whole blood on the binding of these antibodies, as well as investigate the effect of time delay on the staining patterns of these antibodies.

\section{Results}

The scatter plots of SSC versus FSC for lion and tiger peripheral blood leukocytes revealed distinct cell populations similar to that of other mammals (Fig. 1). Based on these

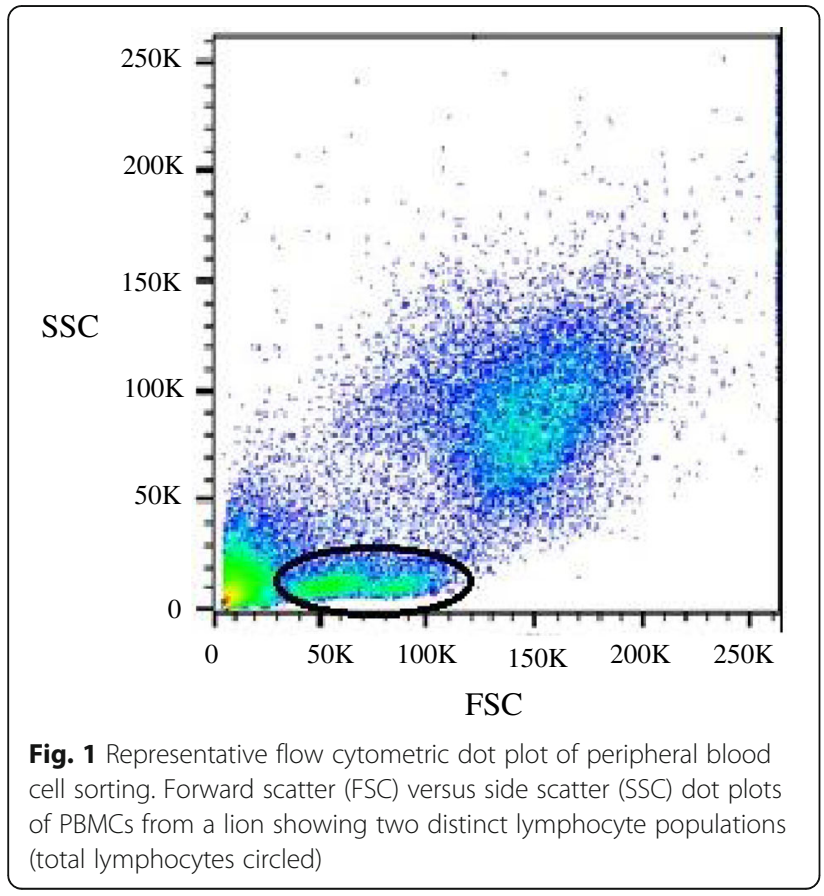

scatter parameters, the percentages of lymphocytes in PBMCs on day 1 were $33.0,20.9 \%$ and 30.3 for lion 1, lion 2 and the tiger, respectively. The percentages of lymphocytes in RCLLs were $24.9,17.8$, and $10.6 \%$ in lion 1, lion 2 and the tiger, respectively. In scatterplots of PBMCs, but not RCLLs, from all three animals, small and large lymphocytes appeared as distinct populations (Fig. 1).

\section{Reactivity with lion leukocytes}

All antibodies (described in Table 1) with the exception of CD4 (clone SK3), CD4 (clone RPA-T4), CD19 (clone SJ25C1), CD19 (clone MB19-1), CD62L (clone DREG-56) and IgM (clone G20-127) showed clear cross-reactivity with lion and tiger leukocyte populations in PBMCs (Additional file 1: Figure S1) and RCLLs (Additional file 1: Figure S2).

\section{Staining pattern}

The two distinct PBMC lymphocyte populations differed both in size and antibody staining characteristics. The smaller lymphocytes were mainly cells staining $\mathrm{CD} 4^{+}$, whereas the larger lymphocytes were predominantly $\mathrm{CD}^{+}$cells (Fig. 2; Table 2). Small $\mathrm{CD}^{+}$cells were primarily $\mathrm{CD}^{-} / \mathrm{CD} 45^{+}$, while large $\mathrm{CD} 4^{+}$cells were primarily $\mathrm{CD}^{+} / \mathrm{CD} 45^{-}$(Fig. 3 , Table 3 ), which is similar to the pattern observed in $\mathrm{CD}^{+}$cells (Fig. 4, Table 4). The CD4:CD8 ratio in total lymphocytes in PMBCs of Lion 1 , Lion 2 and the tiger were 3.5, 7.1 and 1.8, respectively.

The predominant $\mathrm{CD} 4^{+}$subsets identified in the small and large lymphocytes were $\mathrm{CD} 5^{-} \mathrm{CD} 45^{+}$and $\mathrm{CD} 5^{+} \mathrm{CD} 45^{-}$ respectively. These populations were gated on in both PBMCs (small and larger lymphocytes combined) and RCLLs to analyse $\mathrm{CD} 25^{+}$and $\mathrm{CD} 44^{+}$expression. In the PBMC sample, $48.4 \%$ of the $\mathrm{CD} 4^{+} \mathrm{CD} 5^{+} \mathrm{CD} 45^{-}$cells were $\mathrm{CD}_{25} 5^{+}$however this pattern was not mirrored in the RCLL sample (Additional file 1: Table S1). CD44 $4^{+}$cells were observed in both PBMCs and RCLLs, but the expression varied greatly.

Expression of CD14 and CD11b were restricted to lymphocytes that were $\mathrm{CD} 4^{+}$, while $\mathrm{CD}^{+}$lymphocytes showed no evidence of CD14 or CD11b expression. Moreover, CD14 and CD11b were primarily expressed on different $\mathrm{CD} 4^{+}$sub-populations (Fig. 5, Table 5).

\section{Influence of blood processing technique on staining pattern}

CD4 and CD8 antibody staining was comparable in the PBMC and RCLL samples of both lions and the tiger. The staining of CD25, CD14 and CD11b all showed large differences between PBMC and RCLL samples for the two lions, but were comparable for the tiger (Additional file 1: Table S2). 
Table 1 Commercially available antibodies screened for cross-reactivity with African lion lymphocytes

\begin{tabular}{|c|c|c|c|c|c|c|}
\hline \multirow{2}{*}{$\begin{array}{l}\text { Surface } \\
\text { marker }\end{array}$} & \multirow[t]{2}{*}{ Clone } & \multirow[t]{2}{*}{ Reactivity } & \multirow[t]{2}{*}{ Fluorophore } & \multirow[t]{2}{*}{ Company } & \multicolumn{2}{|c|}{ Optimal conc (ug/ml) } \\
\hline & & & & & $\overline{\mathrm{PBMC}}$ & RCLL \\
\hline CD5 & $f 43$ & Feline/ Lion (PBMC) & PE & $\begin{array}{l}\text { Southern Biotech, } \\
\text { Birmingham, AL, USA }\end{array}$ & 0.5 & 0.5 \\
\hline CD4 & $3-4 f 4$ & Feline & FITC & Southern Biotech & 1.75 & 1.75 \\
\hline CD4 & SK3 & Human & $\mathrm{APC}$ & BD Biosciences & $N B^{a}$ & NB \\
\hline CD4 & RPA-T4 & Human & V500 & BD Biosciences & NB & NB \\
\hline \multirow[t]{2}{*}{$\operatorname{CD} 8 \beta$} & fCD8 & Feline & FITC & Southern Biotech & 0.25 & 1.75 \\
\hline & & & PE & Southern Biotech & 0.25 & 3.5 \\
\hline CD11B & $\mathrm{M} 1 / 70$ & Mouse, Human & PERCP-CY 5.5 & Abcam, Cambridge, UK & 1.75 & 3.5 \\
\hline CD14 & $61 \mathrm{D3}$ & $\begin{array}{l}\text { Human, Cynomolgus, } \\
\text { Canine, Hooded Seal }\end{array}$ & APC-CY7 & Southern Biotech & 3.5 & 1.75 \\
\hline CD19 & $\mathrm{SJ} 25 \mathrm{C} 1$ & Human & BV510 & BD Biosciences & NB & NB \\
\hline CD19 & MB19-1 & Mouse, Canine & APC-CY7 & $\begin{array}{l}\text { Life Technologies, Carlsbad, } \\
\text { CA, United States }\end{array}$ & NB & NB \\
\hline CD25 & P4A10 & Canine & Biotin/HRP-HV500 & $\begin{array}{l}\text { Bio-rad, Hercules, CA, } \\
\text { United States }\end{array}$ & 0.5 & 1.75 \\
\hline CD44 & IM7 & Mouse & PERCP-CY5.5 & Southern Biotech & 5 & 5 \\
\hline CD45R & RA3-6B2 & Mouse, Human & APC-CY7 & Southern Biotech & 2.5 & 2.5 \\
\hline CD62L & DREG-56 & Human, Chimpanzee, Cattle & V450 & BD Biosciences & NB & NB \\
\hline $\lg M$ & G20-127 & Human & BV510 & BD Biosciences & NB & NB \\
\hline
\end{tabular}

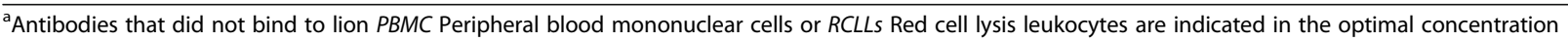
column as NB Non-binding
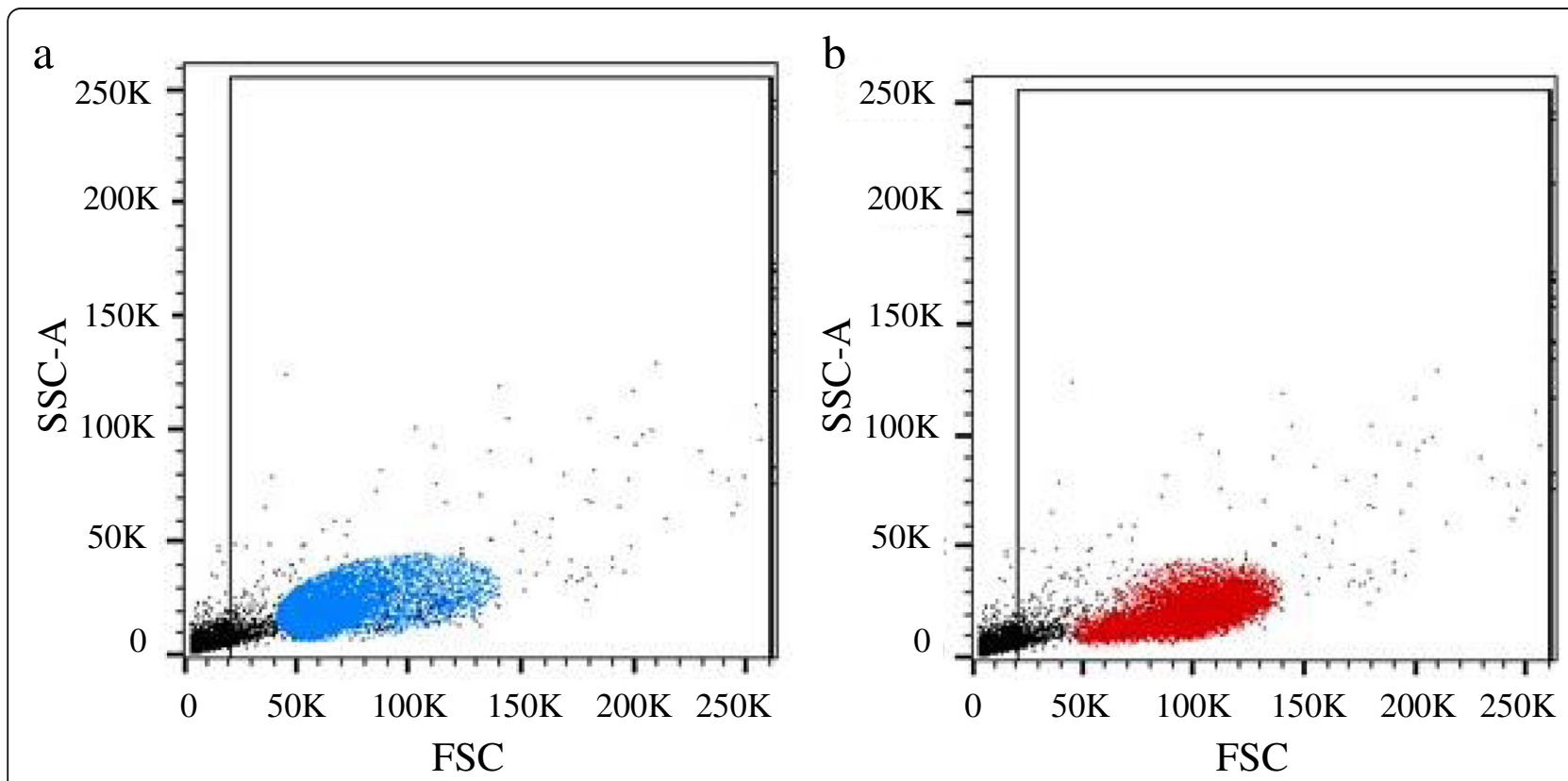

Fig. 2 Representative flow cytometeric scatter plots of PBMCs from a lion indicating the occurrence of two distinct lymphocyte populations. The smaller lymphocytes are mainly comprised of $\mathbf{a}$ CD4+ cells, whereas $\mathbf{b}$ CD8+ cells make up the larger lymphocytes 
Table 2 CD4 and CD8 expression (\%) on small and large lion and tiger lymphocytes in PBMC sample at Day 1

\begin{tabular}{|c|c|c|c|c|c|c|}
\hline & \multicolumn{2}{|c|}{ Total lymphocytes } & \multicolumn{2}{|c|}{ Small lymphocytes } & \multicolumn{2}{|c|}{ Large lymphocytes } \\
\hline & $\overline{\mathrm{CD}^{+}}$ & $\mathrm{CD}^{+}$ & $\overline{\mathrm{CD}^{+}}{ }^{+}$ & $\mathrm{CD}^{+}$ & $\overline{\mathrm{CD}^{+}}{ }^{+}$ & $\mathrm{CD}^{+}$ \\
\hline Lion 1 & 51.9 & 14.8 & 69.0 & 5.06 & 14.5 & 21.5 \\
\hline Lion 2 & 52.9 & 7.5 & 48.3 & 4.60 & 7.03 & 12.5 \\
\hline Tiger & 26.4 & 14.5 & 39.2 & 13.9 & 1.59 & 18.0 \\
\hline
\end{tabular}

\section{Effect of time delay on cell surface staining}

The expression of surface markers over time varied greatly between animals, with relatively stable expression over Day 1 and Day 2 in some markers (i.e. Lion 1 PBMC $\mathrm{CD}^{+}$expression) but not in others (i.e. Lion 1 PBMC CD $25^{+}$expression) (Additional file 1: Tables S3, S4 and S5). The most stably observed populations were both PBMC and RCLL $\mathrm{CD}^{+}$cells, as well as $\mathrm{CD} 4{ }^{+} \mathrm{CD} 5^{-} \mathrm{CD} 45^{+}$PBMCs.

\section{Discussion}

Lymphocytes from both lions and a tiger, isolated by centrifugation over a density gradient, separated into distinct small and large populations. This phenomenon has previously been described in domestic cats [13], but not in lions $[8-10,14]$. The smaller lymphocytes were predominantly characterized as $\mathrm{CD} 4{ }^{+}$, whereas the larger lymphocyte population was mostly $\mathrm{CD}^{+}$cells. This differs from what is seen in domestic cat lymphocytes, which have a higher proportion of $\mathrm{CD}^{+}$cells in the small lymphocyte population [13]. In the total PBMC lymphocyte population the CD4:CD8 ratio varied greatly between the three animals, with both lions having similar or higher ratios than previously reported for healthy African lions [10, 15]. Unlike previous reports of distinct CD8 $\beta$ dim and bright cells observed in $[9,10]$, these subsets were not detected in the present study.

In the present study, CD45, classically known as a pan-lymphocyte marker [16, 17], did not react with all Panthera lymphocyte populations. Studies have reported that CD45R is found on B cells, T cells and thymocytes [18]. The expression of CD45R is particularly noted on activated murine $\mathrm{T}$ cells $[18,19]$. As T lymphocytes express various forms of the leukocyte-common antigen CD45 [19], it is plausible that the CD45- lymphocytes express another isoform of CD45 that was not detected. Additionally, on $\mathrm{CD}^{+}$and $\mathrm{CD}^{+}$lymphocytes, CD5 and CD45 did not co-localize, with the smaller lymphocytes predominantly being $\mathrm{CD} 5^{-} \mathrm{CD} 45^{+}$and the larger lymphocytes $\mathrm{CD}^{+} \mathrm{CD} 45^{-}$. Other authors have considered $\mathrm{CD}^{-}$lion lymphocytes as B cells [10], neglecting the possibility of species specific differences in immune cell surface receptor expression as observed in adult rabbits where all peripheral B lymphocytes express CD5 [20]. This may have led to an over or underestimation of the true percentage of $\mathrm{CD}^{+}$lymphocytes, as only $\mathrm{CD}^{+}$ lymphocytes were considered, excluding any cells which

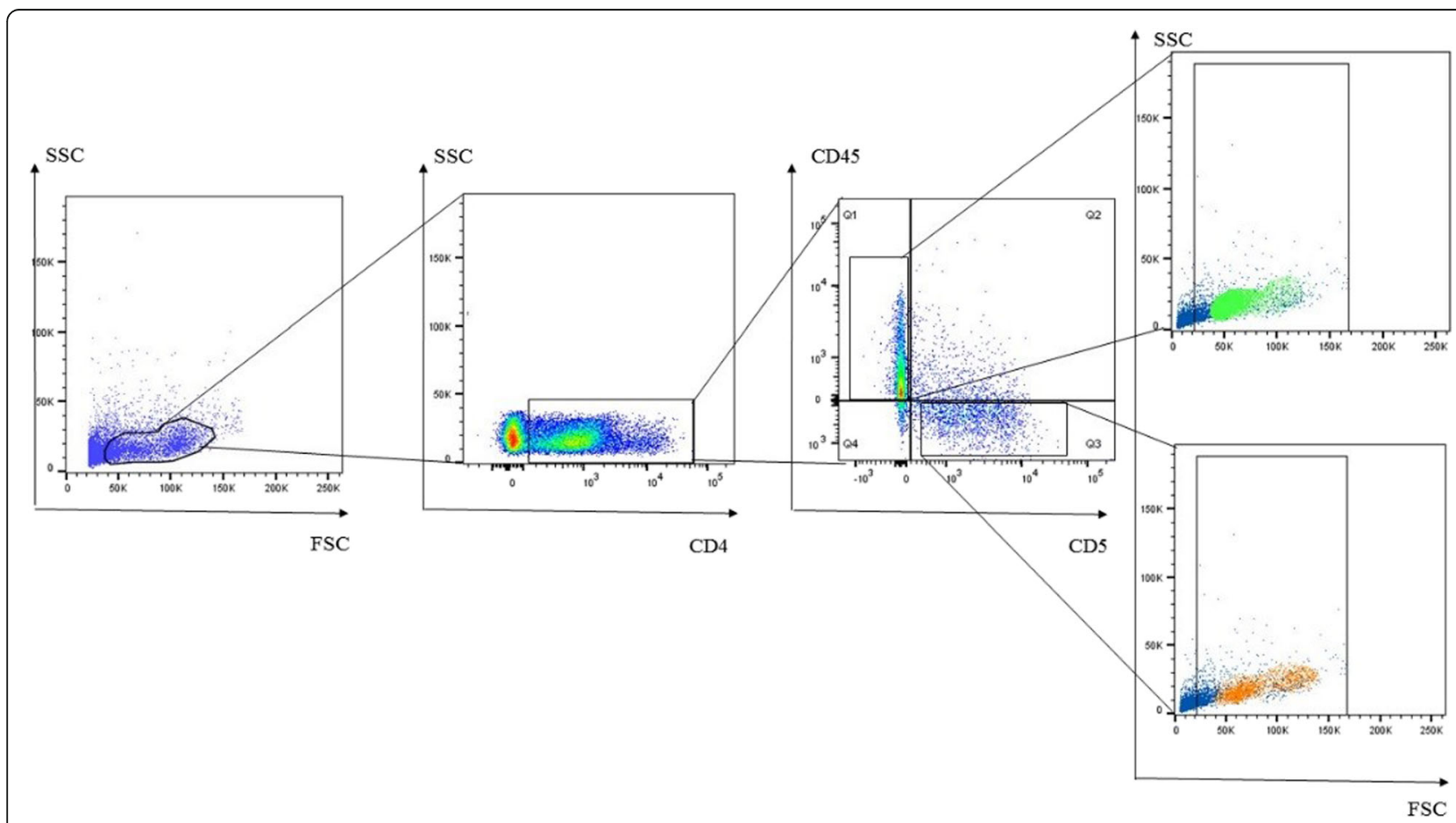

Fig. 3 Representative flow cytometric dot plot of lion PBMCs. CD4 + CD5 + CD45- and CD4 + CD5-CD45+ lymphocytes were selected for back gating to establish their distribution across the two distinct lymphocyte populations observed on the FSC versus SSC dot plots 
Table 3 CD5 and CD45 expression on small and large CD4 ${ }^{+}$cells in Panthera PBMCs (\%) at Day 1 as determined by flow cytometry

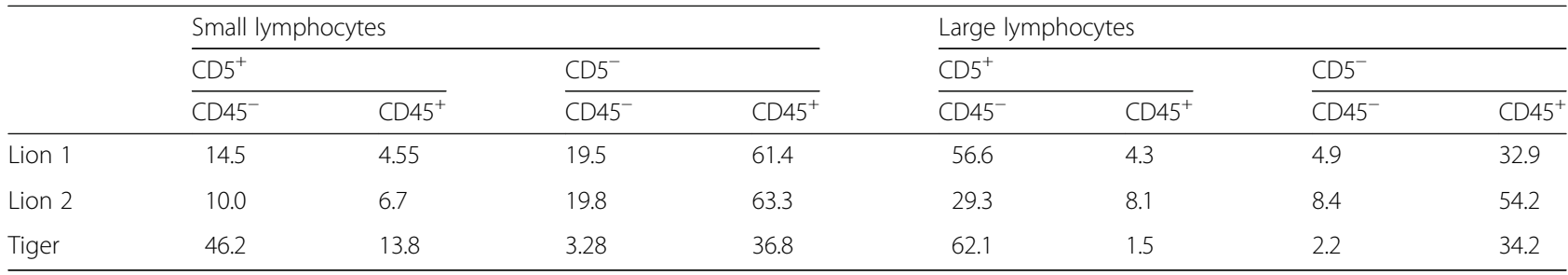

may be $\mathrm{CD} 5^{-} \mathrm{CD} 4^{+}$. Previous studies have described cytotoxic $\mathrm{CD}^{+} \mathrm{CD}^{-} \mathrm{CD}^{+}$cells in humans [21] and activated $\mathrm{CD}^{-} \mathrm{CD}_{4}^{+}$and $\mathrm{CD}^{-} \mathrm{CD}^{+}$cells in ovine lentivirus infected sheep [22]. In Panthera species, markers of activation may be similar, and the expression of CD5, CD45 and CD4 should be investigated further.

Evidence for a highly stable subset of $\mathrm{CD} 8^{+} \mathrm{CD} 5^{-}$cells has been described in humans [23]. These cells are a major source of lymphotactin which is a chemotactic agent for lymphocytes and may play a role in immune regulation [23]. In the present study the majority of $\mathrm{CD}^{+}$lymphocytes were identified as $\mathrm{CD}^{+} \mathrm{CD} 5^{-} \mathrm{CD} 45^{+}$ or $\mathrm{CD}^{+} \mathrm{CD}^{+} \mathrm{CD} 45^{-}$, which has not been previously reported in studies characterizing the immunophenotype of lion cells $[8-10,14]$. These cells may play an important role in immune regulation and should be investigated further.

The co-expression of CD4 and CD14 on the surface of lion lymphocytes was unexpected. Although these may be $\mathrm{CD} 4^{+} \mathrm{CD} 14^{+}$lymphocytes, $\mathrm{CD} 4^{+} \mathrm{CD} 14^{+}$macrophages have been observed in both humans and rats $[24,25]$. These macrophages have been described to play a role in HIV pathogenesis [25] and may be involved in immune responses to FIV in lions. $\mathrm{CD} 8^{+} \mathrm{CD} 14^{+}$lymphocytes have been identified in humans, but not murine, lymphocytes after stimulation and these are able to secrete high levels of interferon gamma, granzyme and perforin [25]. In the present study there was no evidence of $\mathrm{CD} 14$ or $\mathrm{CD} 11 \mathrm{~b}$ expression on $\mathrm{CD}^{+}$cells, however both $\mathrm{CD} 4{ }^{+} \mathrm{CD} 11 \mathrm{~b}^{+}$and $\mathrm{CD} 4{ }^{+} \mathrm{CD} 14^{+}$lymphocytes were observed. The CD11b adhesion protein is associated with $\mathrm{T}$ cell activation, and its expression on $\mathrm{T}$ cells has been associated with persistent bacterial infection [25]. Conversely, CD11b expression on $\mathrm{CD}^{+}$cells are characteristic of viral infections [26]. The current study is the first to describe the expression of CD14 and CD11b on lion lymphocytes. However, a study investigating the effects of FIV on $\mathrm{T}$ lymphocyte populations

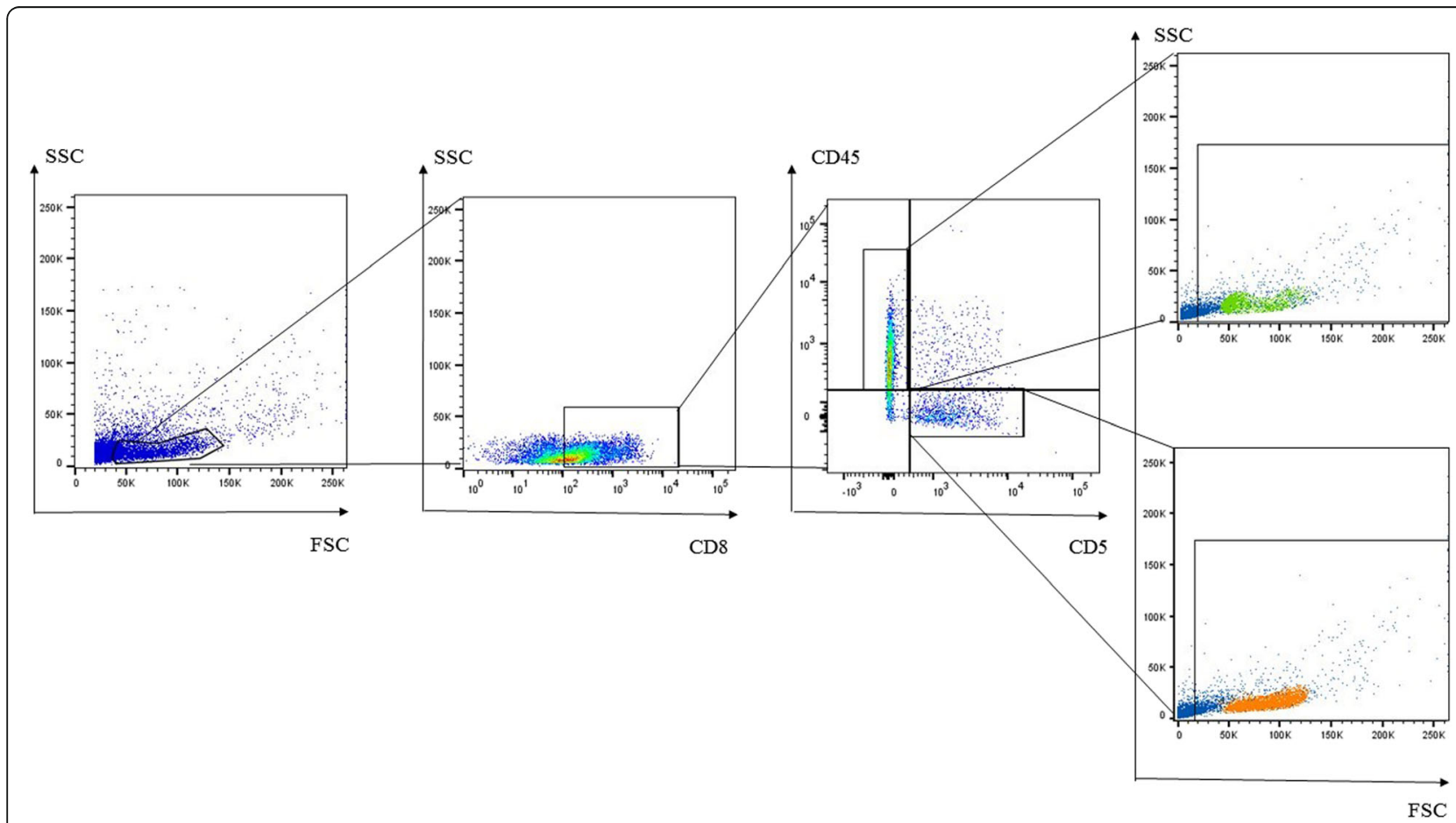

Fig. 4 Representative flow cytometric dot plot of lion PBMCs. CD8 + CD5 + CD45- and CD8 + CD5-CD45+ lymphocytes were selected for back gating to establish their distribution across the two distinct lymphocyte populations observed on the FSC versus SSC dot plots 
Table 4 CD5 and CD45 expression on small and large CD8 ${ }^{+}$cells in Panthera PBMCs (\%) at Day 1 as determined by flow cytometry

\begin{tabular}{|c|c|c|c|c|c|c|c|c|}
\hline & \multicolumn{4}{|c|}{ Small lymphocytes } & \multicolumn{4}{|c|}{ Large lymphocytes } \\
\hline & \multicolumn{2}{|l|}{$\overline{\mathrm{CD}^{+}}$} & \multicolumn{2}{|l|}{$\mathrm{CD}^{-}$} & \multicolumn{2}{|l|}{$\overline{\mathrm{CD}^{+}}$} & \multicolumn{2}{|l|}{$\mathrm{CD}^{-}$} \\
\hline & $\overline{C D 45^{-}}$ & ${\mathrm{CD} 45^{+}}^{+}$ & $\overline{C D 45^{-}}$ & ${\mathrm{CD} 45^{+}}^{+}$ & $\overline{C D 45^{-}}$ & ${\mathrm{CD} 45^{+}}^{-}$ & $\overline{\mathrm{CD} 45^{-}}$ & $\mathrm{CD}_{4} 5^{+}$ \\
\hline Lion 1 & 19.0 & 18.1 & 3.7 & 59.2 & 49.5 & 7.43 & 8.8 & 34.3 \\
\hline Lion 2 & 33.9 & 24.2 & 7.37 & 34.5 & 40.9 & 16.4 & 9.6 & 33.0 \\
\hline Tiger & 62.9 & 19.9 & 7.7 & 9.52 & 78.4 & 7.89 & 4.2 & 9.6 \\
\hline
\end{tabular}

described the expression of CD18, which associates with the 11b integrin chain [27]. Higher expression of CD18, defined as a marker of activation, has also been observed on $\mathrm{CD}^{+} \mathrm{T}$ cells in FIV-positive lions [9], supporting the increased expression of integrins on virally activated cells. These markers should be investigated further, and may provide insights into the mechanism of immune regulation in $M$. bovis or FIV infection.

Previous immunophenotyping studies using lion peripheral blood have investigated the influence of FIV on CD44 and CD49 as activation markers [9]. In the present study however, we describe the novel identification of $\mathrm{CD} 4^{+} \mathrm{CD} 25^{+}$cells in lion PBMCs and RCLLs, with staining patterns similar to that of regulatory $\mathrm{T}$ cells in domestic cats [28]. Lion $\mathrm{CD}_{4} 4^{+}$lymphocytes have also been characterized in the present study using a canine cross-reactive clone, IM7. A previous report described the use of CD44 clone MEM85 in lions, and found CD44 expression to remain unchanged by FIV [9]. The genetic sequence coding for these two clones have been found to be homoglous with different regions of the CD44 gene [29]. Furthermore, the antibody from the MEM85 clone is reported to bind to human CD44, but not canine CD44, whereas the antibody from the IM7 clone was described to be cross-reactive with mouse, dog, non-human primates and humans [29]. CD44 is essential for the generation of memory Th1 cells [30] and also plays a role in cell adhesion and migration, lymphocyte homing, activation and proliferation [31]. In FIV-infected domestic cats, Th1 immune responses have been shown to inhibit virus replication [32]. Investigating the co-localization of IM7 and MEM85 may increase confidence and improve insight

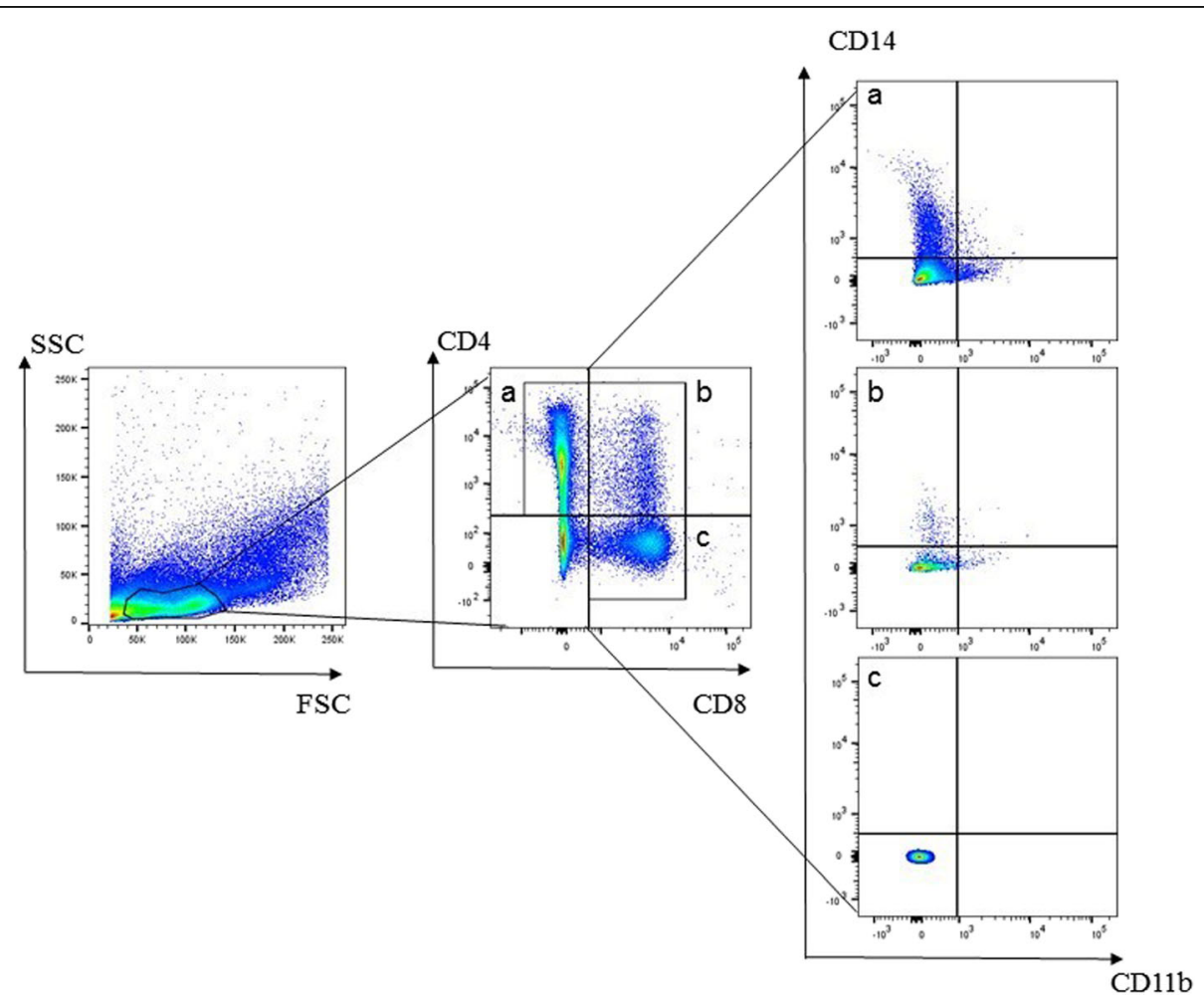

Fig. 5 Flow cytometric dot plot of peripheral blood cell sorting. CD4 + CD8- (a), CD4 + CD8+ (b) and CD4-CD8+ (c) lymphocyte subsets were selected to evaluate CD14 and CD11b expression 
Table 5 CD14 and CD11b expression (\%) on CD $4^{+}$and CD8 ${ }^{+}$ cells in Panthera PBMCs at Day 1 as determined by flow cytometry

\begin{tabular}{|c|c|c|c|c|c|c|}
\hline & \multicolumn{2}{|c|}{$\mathrm{CD}^{+} \mathrm{CD} 8^{-}$} & \multicolumn{2}{|c|}{$\mathrm{CD}^{+} \mathrm{CD}^{+}$} & \multicolumn{2}{|c|}{$\mathrm{CD}_{4}^{-} \mathrm{CD} 8^{+}$} \\
\hline & $\overline{\mathrm{CD} 14^{+}}$ & $\overline{C D} 11 b^{+}$ & $\overline{\mathrm{CD}_{14}{ }^{+}}$ & $\mathrm{CD}_{11 \mathrm{~b}^{+}}$ & $\overline{\mathrm{CD}_{14} 4^{+}}$ & $\mathrm{CD} 11 \mathrm{~b}^{+}$ \\
\hline Lion 1 & 4.56 & 2.34 & 3.92 & 0 & 0 & 0 \\
\hline Lion 2 & 3.86 & 0.97 & 1.55 & 3.10 & 0 & 0 \\
\hline Tiger & 5.63 & 2.33 & 0.56 & 0 & 0 & 0 \\
\hline
\end{tabular}

into the effects of FIV on the CD $44^{+}$directed immune activation in lion lymphocytes.

Due to the remote locations where wild lion populations are found as well as the harsh in-field conditions, the influence of both time to processing as well as the influence of different sampling methods were investigated. The effects of sample processing varied greatly between the animals, with CD4 and CD8 antibody staining being comparable between the PBMC and RCLL samples of both lions and the tiger. Although staining patterns using CD25, CD14 and CD11b in PBMCs and RCLLs were similar in the tiger, they were not in the lions. Previous reports of flow cytometric analysis of T-lymphocyte subsets in cats report that fluorescence intensity was not adversely affected by the whole blood lysis technique [12]. Moreover, the influence of sample processing time on antibody binding was inconclusive, with highly variable patters observed. Further investigation in a larger cohort of animals is required to establish the usefulness of the whole blood lysis technique in lion whole blood, as well as the influence of processing time on antibody binding to cell surface markers. Further validation of the reactivity of these antibodies in Pathera species using transcriptomics will prove useful in confirming and clarifying the lymphocyte subsets observed. Moreover, as FIV infection has been reported to influence the distribution of small and large lymphocytes in domestic cats [13], it may be useful to further investigate lymphocyte activation in these populations in infected lions.

The role of T-lymphocytes in the lion immune response are poorly understood. To our knowledge, this is the first published report on the flow cytometric analysis of tiger lymphocytes and the use of these commercially obtained antibodies in lion RCLLs. Additionally, we describe the presence of possible activated subsets within these samples which may give insight into the mechanism of immune protection during pathogenic infections. A number of previous studies have investigated lion lymphocyte populations by using commercially available antibodies developed for the domestic cat [8-10, 14, 33], demonstrating the conserved nature of cell surface epitopes among felids and the usefulness of using domestic cat-specific antibodies in lions [8].

\section{Conclusion}

This study shows that commercially obtained antibodies are able to recognise cell surface markers in both lion PBMCs and RCLLs, and that there is substantial loss of signal over time, advocating for the timely processing of samples for immunophenotyping. This paper provides a platform which may enable future immune-phenotyping studies to investigate the immune response to FIV and $M$. bovis infections, pathogens commonly affecting the lion populations in South Africa.

\section{Methods}

\section{Animals and sample collection}

Two captive lions (Panthera leo) and one captive tiger (Panthera tigris) were opportunistically sampled from a private game reserve in the Free State, South Africa, during routine health examinations. Blood samples were collected by jugular venipuncture into sodium heparin blood collection tubes and stored at room temperature for 1, 2 and 3 days, respectively (Fig. 6). Approval for this study was obtained from the Stellenbosch University Animal Care and Use Committee (SU-ACUD15-00013). Permission to use the blood obtained from these animals was granted bu. the Head of Animal Welfare at LionsRock Big Cat Sanctuary.

\section{Blood processing}

Two sample processing methods to obtain lymphocytes from whole blood were compared in order to establish whether antibody binding or cell surface receptor expression and detection were influenced by either method.

\section{Red cell lysis of whole blood}

Five hundred microliter aliquots of whole blood harvested on Day 1, 2 and 3 were incubated with $1 \mathrm{ml}$ of Red Cell Lysis Buffer (BD Bioscience, San Jose, CA, USA) in the dark for $10 \mathrm{~min}$, at room temperature. Cells were harvested by centrifugation at $450 \mathrm{x}$ g for $5 \mathrm{~min}$ and washed three times with flow cytometry staining buffer (phosphate-buffered saline (PBS) containing 2\% foetal bovine serum (FBS) (Capricorn Scientific, Ebsdorfergrund, Germany), then resuspended and stored in cryopreservation media consisting of 90\% FBS and 10\% dimethyl sulfoxide (DMSO, Sigma-Aldrich, St. Louis, MO, USA) as three aliquots at $-80^{\circ} \mathrm{C}$. Cell staining was performed within 6 months. Samples obtained using this method will hereafter be referred to as red cell lysis leukocytes (RCLLs).

\section{Density gradient centrifugation}

On Day 1, 2 and 3, $10 \mathrm{ml}$ of whole blood was diluted 1:1 with sterile PBS and layered on $20 \mathrm{ml}$ of Ficoll-Paque (GE 


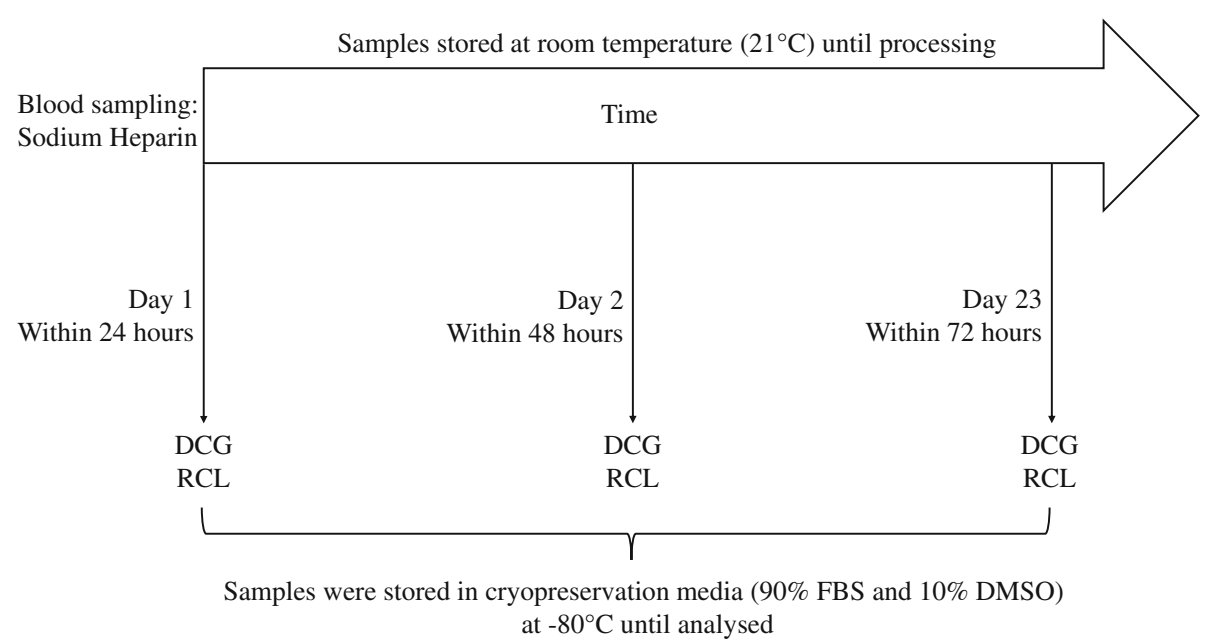

Fig. 6 Whole blood was collected in sodium heparin tubes and stored at room temperature until processed. Samples were processed on Day 1 (within $24 \mathrm{~h}$ of collection), Day 2 (within $48 \mathrm{~h}$ of collection) and Day 3 (within $72 \mathrm{~h}$ of collection), by both red cell lysis (RCL) of the whole blood and density gradient centrifugation (DGC). The processed samples were stored in cryomedia, containing foetal bovine serum (FBS) and dimethyl sulfoxide (DMSO), at $-80^{\circ} \mathrm{C}$

Healthcare Bio-Sciences, Uppsala, Sweden). Samples were centrifuged for $25 \mathrm{~min}$ at $400 \times \mathrm{g}$, without applying a brake. The peripheral blood mononuclear cell (PBMC) interface was carefully aspirated and cells were washed twice with PBS by centrifugation for 10 $\min$ at $400 \times \mathrm{g}$. The PBMCs were resuspended in residual PBS and stored in cryopreservation media as three aliquots at $-80^{\circ} \mathrm{C}$ until staining was performed. Cell staining was performed within 6 months. Samples obtained using this method will hereafter be referred to as PBMCs.

\section{Cell surface receptor staining}

Cells stored at $-80^{\circ} \mathrm{C}$ were thawed in a water bath at $37^{\circ} \mathrm{C}$ and washed twice with staining buffer before being resuspended in $4 \mathrm{ml}$ staining buffer. During initial optimization, $50 \mu \mathrm{l}$ of resuspended cells were incubated with dilutions of fluorophore-labelled antibody (1:5, $1: 10,1: 25,1: 50,1: 100$ and 1:200), with final concentrations of antibody at $0.25-5 \mu \mathrm{g} / \mathrm{ml}$ (Table 1). The optimal antibody concentration was determined as previously described [9]. The cells were stained at the optimal concentration for $60 \mathrm{~min}$ at $4{ }^{\circ} \mathrm{C}$ in the dark, with manual agitation $30 \mathrm{~min}$ into the staining protocol. After staining, cells were washed according to manufacturer's instructions. A FACS Canto II (BD Bioscience) was used for cell acquisition ( $\geq 10,000$ events). The instrument was calibrated and setup according to the manufacturer's instructions. Quality controls included the use of Rainbow Beads (eBioscience-San Diego, CA, USA) and $\mathrm{BD}^{\mathrm{m}}$ CompBeads to adjust the compensation settings accordingly.

\section{Gating strategy}

In order to identify lymphocyte populations, doublets were excluded using forward scatter (FSC) area versus FSC height as previously described [11]. Following exclusion of debris, lymphocyte subsets were identified and other cell types, including monocytes, excluded based on FSC and side scatter (SSC) characteristics, as for other species $[11,12]$. From this gate, $\mathrm{CD} 4^{+}, \mathrm{CD} 4^{-}$, $\mathrm{CD}^{+}$or $\mathrm{CD}^{-} \mathrm{T}$ lymphocytes were selected for further analysis depending on the panel analysed. The PBMCs and RCLLs were stained with three different antibody combinations: Panel 1: CD5, CD4, CD25, CD44, CD45; Panel 2: CD4, CD8, CD14, CD11b; and Panel 3: CD 5, CD8, CD45. The initial strategy first gated on all CD45+ cells (as is the standard approach), however due to large proportion of the lymphocytes being excluded from the analysis, as well as the observation of a large subset of $\mathrm{CD} 4+$ cells which did not express CD45, the gating strategy was changed to the above. Based on our current understanding of the human immune system we do not expect CD4+ cells to not express CD45, but due to species specific differences observed by other authors [20] this possibility in lions cannot be ruled out.

\section{Data and statistical analysis}

All data were analysed using FlowJo Version 10 software (Tree Star, Ashland, OR, USA). Nonparametric tests (Mann-Whitney U tests) were used to compare antibody staining patterns over time. A $p$-value of 0.05 or less was considered significant. All statistical analyses were performed using GraphPad Prism version 5.00 (GraphPad Software, Inc., La Jolla, CA, USA). 


\section{Additional file}

Additional file 1: Figure S1. Staining profiles for commercially available antibodies a) (D4, b) CD8, c) CD44, d) CD5, e) CD45, f) CD25, g) CD14 and h) CD11b that showed evidence of cross-reactivity with Panthera lymphocytes in the PBMC sample. Figure S2. Staining profiles for commercially available antibodies a) (D4, b) (D8, c) CD44, d) CD5, e) CD45, f) CD25, g) CD14 and h) CD11b that showed evidence of cross-reactivity with Panthera lymphocytes in the RCLL sample. Table S1. CD44 and CD25 expression on CD4 + CD5 + CD45- and CD4 + CD5-CD45+ lymphocytes in PBMCs and RCLLs (\%) at Day 1. Table S2. Expression of cell surface markers (\%) in Panthera species PBMCs versus RCLLs on Day 1. Table S3. Cell surface marker expression (\%) on lymphocytes in PBMC and RCLL samples of Lion 1 over time. Table S4. Cell surface marker expression (\%) on lymphocytes in PBMC and RCLL samples of Lion 2 over time. Table S5. Cell surface marker expression (\%) on lymphocytes in PBMC and RCLL samples of the tiger over time. (PDF $456 \mathrm{~kb}$ )

\section{Abbreviations}

DMSO: Dimethyl sulfoxide; FBS: Foetal bovine serum; FIV: Feline immunodeficiency virus; FSC: Forward scatter; PBMC: Peripheral blood mononuclear cell; PBS: Phosphate buffered saline; RCLL: Red cell lysis lecukocyte; SSC: Side scatter

\section{Acknowledgements}

The authors wish to acknowledge Dr. Peter Caldwell and the staff at the Old Chapel Veterinary Clinic as well as the team at Lionsrock Big Cat Sanctuary and Four Paws for their assistance with this study. Financial support for this project was provided by the American Association of Zoo Veterinarians Wildlife Health Fund (Grant 2015-06), NRF South African Research Chair Initiative (Grant NRF 86949), and South African Medical Research Council. We declare that the content of this publication is the sole responsibility of the authors and that the funding agencies were not involved in any of the research design, implementation, analyses, or writing. Therefore, the publication does not necessarily represent the views of the funders.

\section{Funding}

Financial support for this project was provided by Morris Animal Foundation (Grant D10ZO-039), American Association of Zoo Veterinarians Wildlife Health Fund (Grant 2015-06), the NRF South African Research Chair Initiative (Grant NRF 86949) and the South African Medical Research Council. The content is solely the responsibility of the authors and does not necessarily represent the views of these bodies.

\section{Availability of data and materials}

All data generated or analysed during this study are included in this published article and its additional files.

\section{Authors' contributions}

TTS contributed to the study design, performed all the experiments, analysed the data and drafted the manuscript. MAM and PDVH participated in data interpretation and editing of the manuscript. SDCP contributed to the study design, data interpretation and editing of the manuscript. AGL conceived the study and contributed to the study design, participated in analysing the data and drafting the manuscript. All authors have read and approved the final manuscript.

\section{Ethics approval}

Approval for this study was obtained from the Stellenbosch University Animal Care and Use Committee (ACU/2010/007 and SU-ACUD15-00013).

\section{Consent for publication}

Not applicable.

\section{Competing interests}

The authors declare that they have no competing interests.

\section{Publisher's Note}

Springer Nature remains neutral with regard to jurisdictional claims in published maps and institutional affiliations.

Received: 25 April 2018 Accepted: 26 November 2018

Published online: 19 December 2018

\section{References}

1. Furman D, Davis MM. New approaches to understanding the immune response to vaccination and infection. Vaccine. 2015;33:5271-81. https://doi. org/10.1016/j.vaccine.2015.06.117.

2. Estes JA, Terborgh J, Brashares JS, Power ME, Berger J, Bond WJ, Carpenter SR, Essington TE, Holt RD, Jackson JBC, Marquis RJ, Oksanen L, Oksanen T, Paine RT, Pikitch EK, Ripple WJ, Sandin SA, Scheffer M, Schoener TW, Shurin JB, Sinclair ARE, Soulé ME, Virtanen R, Wardle DA. Trophic downgrading of planet earth. Science. 2011;333:301-6.

3. Pedersen AB, Babayan SA. Wild immunology. Mol Ecol. 2011;20:872-80. https://doi.org/10.1111/j.1365-294X.2010.04938.x.

4. Abolins SR, Pocock MJO, Hafalla JCR, Riley EM, Viney ME. Measures of immune function of wild mice, Mus musculus. Mol Ecol. 2011;20:881-92. https://doi.org/10.1111/j.1365-294X.2010.04910.x

5. Nussey DH, Watt KA, Clark A, Pilkington JG, Pemberton JM, Graham AL, McNeilly TN. Multivariate immune defences and fitness in the wild: complex but ecologically important associations among plasma antibodies, health and survival. Proc R Soc B. 2013;281:20132931. https://doi.org/10.1098/rspb.2013.2931.

6. Ridpath JF, Passler T. Editorial: control of pestivirus infections in the management of wildlife populations. Front Microbiol. 2016;7:1396. https:// doi.org/10.3389/fmicb.2016.01396.

7. Bradley JE, Jackson JA. Measuring immune system variation to help understand host-pathogen community dynamics. Parasitology. 2008. https://doi.org/10.1017/S0031182008000322

8. Spencer JA, Bouic PD, Espie I, Colly L. A comparison between T-helper (CD4) and T-suppressor (CD8) cell ratios in FIV positive and negative lions Panthera leo and domestic cats Felis catus. South Afr J Wildl Res. 1995;25:111.

9. Bull ME, Kennedy-Stoskopf S, Levine JF, Loomis M, Gebhard DG, Tompkins WAF. Evaluation of T lymphocytes in captive African lions (Panthera leo) infected with feline immunodeficiency virus. Am J Vet Res. 2003:64:1293-300.

10. Roelke ME, Pecon-Slattery J, Taylor S, Citino S, Brown E, Packer C, VandeWoude S, O'Brien SJ. T-lymphocyte profiles in FIV-infected wild lions and pumas reveal CD4 depletion. J Wildl Dis. 2006;42:234-48. https://doi. org/10.7589/0090-3558-42.2.234.

11. Autissier P, Soulas C, Burdo TH, Williams KC. Immunophenotyping of lymphocyte, monocyte and dendritic cell subsets in normal rhesus macaques by 12-color flow cytometry: clarification on DC heterogeneity. J Immunol Methods. 2010;360:119-28. https://doi.org/10.1016/j.jim.2010.06.017.

12. Dean GA, Quackenbush SL, Ackley CD, Cooper MD, Hoover EA. Flow cytometric analysis of T-lymphocyte subsets in cats. Vet Immunol Immunopathol. 1991;28:327-35. https://doi.org/10.1016/0165-2427(91)90124-U.

13. Walker C, Bao S, Canfield PJ. Analysis of feline dual lymphocyte populations observed by flow cytometry. Vet Immunol Immunopathol. 1995:48:11-25. https://doi.org/10.1016/0165-2427(95)05421-2.

14. Bull ME, Gebhard DG, Tompkins WAF, Kennedy-Stoskopf S. Polymorphic expression in the CD8alpha chain surface receptor of African lions (Panthera leo). Vet Immunol Immunopathol. 2002:84:181-9.

15. Broughton HM, Govender D, Shikwambana P, Chappell P, Jolles A. Bridging gaps between zoo and wildlife medicine: establishing reference intervals for free-rnaging African lions (Panthera leo). J Zoo Wildl Med. 2017;48:298-311.

16. Hunt P, Else RW, McConnell I, Hopkins J. Identification of CD45 (leucocyte common antigen) in the domestic cat. Res Vet Sci. 1995;59:201-4.

17. van Lochem EG, van der Velden VH, Wind HK, te Marvelde JG, Westerdaal NA, van Dongen JJ. Immunophenotypic differentiation patterns of normal hematopoiesis in human bone marrow: reference patterns for age-related changes and disease-induced shifts. Cytometry B Clin Cytom. 2004;60B:1-13. https://doi.org/10.1002/cyto.b.20008.

18. Birkeland ML, Johnson $\mathrm{P}$, Trowbridge IS, Puré E. Changes in CD45 isoform expression accompany antigen-induced murine T-cell activation. Proc Natl Acad Sci U S A. 1989:86:6734-8.

19. Watanabe $Y$, Akaike T. Activation signal induces the expression of $B$ cell-specific CD45R epitope (6B2) on murine T cells. Scand J Immunol. 1994;39:419-25 
20. Raman C, Knight KL. CD5 ${ }^{+}$B cells predominate in peripheral tissues of rabbit. J Immunol. 1992;149:3858-64.

21. Spour EF, Leemhuis T, Jenski L, Redmond R, Fillak D, Jansen J. Characterization of normal human $\mathrm{CD}^{+} \mathrm{CD}^{-}$and gamma delta $\mathrm{T}$ cell receptor positive T lymphocytes. Clin Exp Immunol. 1990;80:114-21.

22. Watt NJ, MacIntyre N, Collie D, Sargan D, McConnell I. Phenotypic analysis of lymphocyte populations in the lungs and regional lymphoid tissue of sheep naturally infected with maedi visna virus. Clin Exp Immunol. 1992;90: 204-8. https://doi.org/10.1111/j.1365-2249.1992.tb07929.

23. Stievano L, Tosello V, Marcato N, Rosato A, Sebelin A, Chieco-Bianchi L, Amadori A. $C D 8^{+} a \beta^{+} T$ cells that lack surface $C D 5$ antigen expression are a major lymphotactin (XCL1) source in peripheral blood lymphocytes. J Immunol. 2003;171:4528-38. https://doi.org/10.4049/jimmunol.171.9.4528.

24. Zhen A, Krutzik SR, Levin BR, Kasparian S, Zack JA, Kitchen AG. CD4 ligation on human blood monocytes triggers macrophage differentiation and enhances HIV infection. J Virol. 2014;88:9934-46. https:/doi.org/10.1128/JVI.00616-14.

25. Kotsougiani D, Pioch M, Prior B, Heppert V, Hänsch GM, Wagner C. Activation of T lymphocytes in response to persistent bacterial infection: induction of CD11b and of toll-like receptors on T cells. Int J Inflamm. 2010. https://doi.org/10.4061/2010/526740.

26. Fiorentini S, Licenziati S, Alessandri G, Castelli F, Caligaris S, Bonafede M, Grassi M, Garrafa E, Balsari A, Turano A, Caruso A. CD11b expression identifies $\mathrm{CD}^{+} \mathrm{CD}_{28}{ }^{+} \mathrm{T}$ lymphocytes with phenotype and function of both naive/memory and effector cells. J Immunol. 2001;166:900-7.

27. Dana N, Fathallah DM, Arnaout MA. Expression of a soluble and functional form of the human beta 2 integrin CD11b/CD18. Proc Natl Acad Sci U S A. 1991;88:3106-10

28. Joshi A, Vahlenkamp TW, Garg H, Tompkins WAF, Tompkins MB. Preferential replication of FIV in activated CD4(+)CD25(+)T cells independent of cellular proliferation. Virology. 2004;321:307-22. https://doi.org/10.1016/j.virol.2004.01.014.

29. Sandmaier BM, Storb R, Bennett KL, Appelbaum FR, Santos EB. Epitope specificity of CD44 for monoclonal antibody-dependent facilitation of marrow engraftment in a canine model. Blood. 1998;91:3494-502.

30. Baaten BJ, Li C-R, Bradley LM. Multifaceted regulation of T cells by CD44. Commun Integr Biol. 2010;3:508-12. https://doi.org/10.4161/cib.3.6.13495.

31. Guan H, Nagarkatti PS, Nagarkatti M. Role of CD44 in the differentiation of Th1 and Th2 cells: CD44-deficiency enhances the development of Th2 effectors in response to sheep RBC and chicken ovalbumin. J Immunol. 2009;183:172-80. https://doi.org/10.4049/jimmunol.0802325.

32. Guardo GD. Cat transgenesis and feline versus human AIDS. Vet Pathol. 2012;49:882-3

33. Brennan G, Podell MD, Wack R, Kraft S, Troyer JL, Bielefeldt-Ohmann H, VandeWoude S. Neurologic disease in captive lions (Panthera leo) with lowtiter lion lentivirus infection. J Clin Microbiol. 2006;44:4345-52. https://doi. org/10.1128/JCM.00577-06

Ready to submit your research? Choose BMC and benefit from:

- fast, convenient online submission

- thorough peer review by experienced researchers in your field

- rapid publication on acceptance

- support for research data, including large and complex data types

- gold Open Access which fosters wider collaboration and increased citations

- maximum visibility for your research: over $100 \mathrm{M}$ website views per year

At $\mathrm{BMC}$, research is always in progress.

Learn more biomedcentral.com/submissions 